\title{
Postcardiotomy VA-ECMO for refractory cardiogenic shock
}

\author{
Michael Charlesworth ${ }^{1 *}$, Rajamiyer Venkateswaran ${ }^{2}$, Julian M. Barker ${ }^{3}$ and Lee Feddy ${ }^{3}$
}

\begin{abstract}
Postcardiotomy cardiogenic shock (PCCS) is a rare but catastrophic syndrome that can occur following separation from cardiopulmonary bypass or at any time during the immediate postoperative course. The management of PCCS varies between clinicians, institutions and countries. The available evidence to guide this practice is limited. In their systematic review and meta-analysis, Khorsandi and colleagues report a synthesis of case-series pertinent to the use of venoarterial extracorporeal membrane oxygenation (VA-ECMO) for PCCS. Whilst we acknowledge the potential survival benefit for carefully selected patients for what is ordinarily a condition with high mortality, we wish to comment on several aspects of the study in the context of its application to clinical practice.
\end{abstract}

Keywords: Postcardiotomy, VA-EMO, Systematic review, Cardiogenic shock

In their systematic review and meta-analysis of venoarterial extracorporeal membrane oxygenation (VA-ECMO) for postcardiotomy cardiogenic shock (PCCS), Khorsandi and colleagues report a pooled survival to hospital discharge of $30.8 \%$ and suggest a number of adverse prognostic indicators [1]. Whilst we agree that postcardiotomy VA-ECMO for refractory cardiogenic shock does indeed provide a significant survival benefit, we wish to highlight several limitations so as to aid interpretation of this study and inform future analyses.

With regards the search strategy, it was unclear from which database(s) (Medline and/or PubMed) articles were retrieved and from when the search extends. A recent Cochrane review advised against the pooling of studies from prior to 2000 due to significant advances in technology, yet three of the included studies are from the 1990s [2]. The use of other databases, a Google ${ }^{\mathrm{Tu}}$ search and searching the bibliography of included manuscripts could have ensured a more comprehensive strategy. With regards inclusion and exclusion criteria, all transplant and non-transplant patients receiving VA-ECMO for postcardiotomy cardiogenic shock were included. At our institution, it is generally more common for VA-ECMO to be employed following heart

\footnotetext{
* Correspondence: mda05mc@gmail.com;

${ }^{1}$ Department of Cardiothoracic Anaesthesia, University Hospital South

Manchester, Southmoor Road, Manchester M23 9LT, UK

Full list of author information is available at the end of the article
}

transplantation than it is following non-transplant cardiac surgery. Anecdotally, we also find that outcomes following planned VA-ECMO use following heart transplantation are better as compared to unplanned non-transplant postcardiotomy VA-ECMO. Given that transplant and non-transplant patients have very different baseline characteristics together with different pre, intra and postoperative courses, it may have been advisable to statistically treat transplant and non-transplant groups separately to further reduce data heterogeneity. The finding that all studies were observational in design and with many employing retrospective data collection, is shared by our systematic review of extracorporeal life support for postcardiotomy cardiogenic shock [3]. We also found considerable difficulty in retrieving all relevant articles due to variable definitions of PCCS and extracorporeal life support (ECLS) in the literature.

With regards outcome selection, the authors were limited by outcomes reported from individual studies. These outcomes varied as a function of survival time from mechanical support through to hospital discharge. As hospital discharge was commonly reported, this appears to have been pooled in the meta-analysis. Hospital discharge as a primary outcome has several limitations, as whilst it is commonly affected by non-clinical factors, it does not have a dependence on time and it tells us little about quality of life or other outcomes of interest to patients. With regards reported complication rates, 
retrospective data suffers from underreporting, and the true incidence is therefore difficult to determine. This is of great importance as a major barrier in the way of VAECMO commissioning in the UK is concern regarding complication rates. With regards the combination of outcomes in the meta-analysis, the authors are right to highlight the considerable data heterogeneity. This is not surprising given the design of the included studies. Whilst a critical appraisal of included studies together with survival data pooling is of great interest, it is uncertain what there is to be gained through more advanced statistical manipulation of these data.

Postcardiotomy VA-ECMO is an evolving science with a limited evidence base and with many barriers in the way of high-quality evidence generation [4]. This study poses ethical dilemmas regarding regional variations in decision-making, expertise and outcomes. As highlighted by Khorsandi et al., there are also significant ethical and logistical issues that preclude a randomised controlled trial. That said, this study demonstrates that VA-ECMO is far beyond experimental, as a significant number of patients are surviving that would not otherwise have done so. The decision to initiate postcardiotomy VAECMO is high-stakes due to the potential for poor outcomes from refractory PCCS without VA-ECMO on the one hand but with considerable resource expense on the other. In the UK, these costs are currently absorbed by individual hospitals. At our centre, the decision is taken following discussion and consensus between four appropriately experienced consultants. We have demonstrated our 30-day and 2-year survival rates to be $50 \%$ and as this is somewhat higher than the studies included by Khorsandi et al., we believe that we are currently getting these difficult decisions right through appropriate patient selection [5].

\section{Abbreviations}

ECLS, Extracorporeal life support; PCCS, Postcardiotomy cardiogenic shock; VA-ECMO, Venoarterial extracorporeal membrane oxygenation

\section{Acknowledgments}

None to declare

\section{Funding}

No funding

\section{Availability of data and materials}

Data sharing not applicable to this article as no datasets were generated or analysed during the current study.

\section{Authors' contributions}

All authors contributed significantly to the drafting of this manuscript and all authorise the final version for consideration for publication.

Ethics approval and consent to participate

Not applicable

Consent for publication

Not applicable

\section{Competing interests}

The authors declare that they have no competing interests.

Author details

${ }^{1}$ Department of Cardiothoracic Anaesthesia, University Hospital South Manchester, Southmoor Road, Manchester M23 9LT, UK. ${ }^{2}$ Cardiac and Transplant Surgeon, University Hospital South Manchester, Manchester, UK. ${ }^{3}$ Cardiothoracic Anaesthesia, Critical Care and ECMO, University Hospital South Manchester, Manchester, UK.

\section{References}

1. Khorsandi M, Dougherty S, Bouamra O, Pai V, Curry P, Tsui S, Clark S, Westaby S, Al-Attar N, Zamvar V. Extra-corporeal membrane oxygenation for refractory cardiogenic shock after adult cardiac surgery: a systematic review and meta-analysis. J Cardiothorac Surg 2017;12:55. Available at: http://www.ncbi.nlm.nih.gov/ pmc/articles/PMC5512816/.

2. Tramm R, Ilic D, Davies AR, Pellegrino VA, Romero L, Hodgson C. Extracorporeal membrane oxygenation for critically ill adults. Cochrane Database Syst Rev:CD010381.

3. Charlesworth M, Venkateswaran R, Barnard J, Barker J, Feddy L. Unplanned extracorporeal life support (ECLS) following cardiac surgery: a systematic review. Anaesthesia 2017;72(S4).

4. Charlesworth M, Venkateswaran R, Feddy L. When traditional research fails - the case for veno-arterial ECMO in postcardiotomy cardiogenic shock. Anaesthesia 2017; 72:1425.

5. Charlesworth M, Hernandez A, Feddy L, Barker J, Shaw S, Barnard J, Venkateswaran R. Post-cardiotomy extra corporeal life support (ECLS) for refractory cardiogenic shock: a 4-year retrospective case-note audit in South Manchester, UK. J Cardiothorac Vasc Anesth 2017;31:S83-4.

\section{Authors' response}

RE: Extra-corporeal membrane oxygenation for refractory cardiogenic shock after adult cardiac surgery: a systematic review and meta-analysis

Maziar Khorsandi ${ }^{1 *}$, Scott Dougherty ${ }^{2}$, Omar Bouamra $^{3}$, Vasudev Pai ${ }^{4}$, Philip Curry ${ }^{1}$, Steven Tsui ${ }^{5}$, Stephen Clark ${ }^{6}$, Stephen Westaby ${ }^{7}$,

Nawwar Al-Attar ${ }^{1}$ and Vipin Zamvar ${ }^{8}$

\section{Keywords}

Postcardiotomy, ECMO, Cardiogenic shock, Systematic review

Dear Editor,

We would like to thank Charlesworth et al. for their letter. They have highlighted a few important points, which we would like to take the opportunity to reply to. 
The PubMed search strategy has been clearly delineated under the methods subheading as three different searches (labelled 1-3). As far as we are concerned "MEDLINE" is the primary component of "PubMed" and a search in the latter should yield all the available articles on the topic from the "National Library of Medicine (NLM)". MEDLINE provides 24 million references and PubMed contains 27 million (includes all of MEDLINE references) [6]. We have already stated in the methods section that the search was conducted with "no limit to the year of publication" in order to gain the maximum number of PubMed cited articles. We have also stated that we have performed the search in January of 2017.

In order to obtain the highest impact articles during this project we opted to exclusively look at PubMed/ MEDLINE in order to avoid compiling excessive number of papers that would not change the message conveyed by the study. Hence we performed a cursory Google ${ }^{\mathrm{rx}}$ search only to ensure that we had caught the most high yield articles published up to that time. We also reviewed the bibliography of the obtained articles to look for any other studies, which were not captured in our original search.

The reason why we did not separate the postcardiotomy extracorporeal membrane oxygenation (ECMO) patient into transplant and non-transplant cohorts was the limited number of studies and the limited number of subjects within each study (table 1) [ 7]. We felt that in order for a meta-analysis to have the best chance at yielding any statistical significance these cohorts should be combined, albeit at the expense of greater heterogeneity. Furthermore, there is a great deal of variation in how each study has reported its outcomes and follow-up data and since there is no international consensus in reporting such data, this will continue to be a limitation in any systematic review reporting "post-intervention" outcomes.

We do regard the University Hospital of South Manchester (UHSM) very highly and would have certainly included their outcomes in our study had any outcome data been published at the time of the drafting of our manuscript. We believe that given the exceptionally high survival rate at the UHSM for postcardiotomy ECMO, it would be beneficial for the wider audience if any methods or protocols used at the UHSM to be shared.

Thank you.

Khorsandi et al.,

\section{Abbreviations}

ECMO: extracorporeal membrane oxygenation; NLM: National library of medicine; UHSM: University Hospital of South Manchester
Availability of data and materials

These can be obtained from the corresponding author (M. Khorsandi)

\section{Author contributions}

MK: first author, SD: manuscript drafting, OB: manuscript drafting, VP: manuscript drafting, PC: manuscript drafting, ST: manuscript drafting, SC: manuscript drafting, SW: manuscript drafting, NAA: manuscript drafting, VZ: Senior author, manuscript drafting

Funding

None received

Ethics approval and consent to participate

Not applicable as this is a meta-analysis

Consent for publication

Not applicable as this is a meta-analysis

\section{Competing interests}

Professor Vipin Zamvar is the Editor-in-Chief of the Journal of Cardiothoracic Surgery.

\section{Publisher's Note}

Springer Nature remains neutral with regard to jurisdictional claims in published maps and institutional affiliations.

\section{Author details}

${ }^{1}$ Department of Cardiac Surgery and Transplantation Golden Jubilee National Hospital, Glasgow, UK

${ }^{2}$ Department of Cardiology, Ninewells hospital, Dundee, UK

${ }^{3}$ Medical Statistics, Trauma, Audit \& Research Network University of

Manchester, Salford Royal NHS foundation trust, Manchester, UK

${ }^{4}$ Department of Cardiovascular and Thoracic Surgery, Kasturba Medical

College, Manipal university, Manipal, India

${ }^{5}$ Department of Cardiac Surgery and Transplantation, Papworth hospital,

Cambridge, UK

${ }^{6}$ Department of Cardiac surgery and Transplantation, Freeman hospital,

Newcastle, UK

${ }^{7}$ Department of Cardiac Surgery, Oxford Heart Center, John Radcliffe

Hospital, Oxford, UK

${ }^{8}$ Department of Cardiothoracic Surgery, Royal Infirmary of Edinburgh,

Edinburgh, UK

Received: 1 September 2017 Accepted: 21 November 2017

Published online: 19 December 2017

\section{References}

6. MEDLINE, PubMed, and PMC (PubMed Central). How are they different? Maryland: National Library of Medicine; 2017. Available from: https://http:// www.nlm.nih.gov/pubs/factsheets/dif_med_pub.html. Cited 31 Aug 2017

7. Khorsandi M, Dougherty S, Bouamra O, Pai V, Curry P, Tsui S, et al. Extracorporeal membrane oxygenation for refractory cardiogenic shock after adult cardiac surgery: a systematic review and meta-analysis. J Cardiothorac Surg. 2017;12:55.

Submit your next manuscript to BioMed Central and we will help you at every step:

- We accept pre-submission inquiries

- Our selector tool helps you to find the most relevant journal

- We provide round the clock customer support

- Convenient online submission

- Thorough peer review

- Inclusion in PubMed and all major indexing services

- Maximum visibility for your research

Submit your manuscript at www.biomedcentral.com/submit 